University of South Carolina

Scholar Commons

$11-2009$

\title{
A Cost Analysis of a Physical Activity Intervention for Older Adults
}

Erik J. Groessl

Robert M. Kaplan

Steven N. Blair

University of South Carolina - Columbia, sblair@mailbox.sc.edu

W. Jack Rejeski

Jeffrey A. Katula

See next page for additional authors

Follow this and additional works at: https://scholarcommons.sc.edu/

sph_epidemiology_biostatistics_facpub

Part of the Public Health Commons

\section{Publication Info}

Published in Journal of Physical Activity and Health, Volume 6, Issue 6, 2009, pages 767-774.

Groessl, E. J., Kaplan, R. M., Blair, S. N., Rejeski, W. J., Katula, J. A., King, A. C., ... Pahor, M. (2009). A cost analysis of a physical activity intervention for older adults. Journal of Physical Activity and Health, 6(6), 767-774.

(c) Journal of Physical Activity and Health, 2009, Human Kinetics

This Article is brought to you by the Epidemiology and Biostatistics at Scholar Commons. It has been accepted for inclusion in Faculty Publications by an authorized administrator of Scholar Commons. For more information, please contact digres@mailbox.sc.edu. 


\section{Author(s)}

Erik J. Groessl, Robert M. Kaplan, Steven N. Blair, W. Jack Rejeski, Jeffrey A. Katula, Abby C. King, Roger A. Fielding, Nancy W. Glynn, and Marco Pahor 


\title{
A Cost Analysis of a Physical Activity Intervention for Older Adults
}

\author{
Erik J. GroessI, Robert M. Kaplan, Steven N. Blair, W. Jack Rejeski, Jeffrey A. Katula, \\ Abby C. King, Roger A. Fielding, Nancy W. Glynn, and Marco Pahor
}

We examined the costs of a physical activity (PA) and an educational comparison intervention. 424 older adults at risk for mobility disability were randomly assigned to either condition. The PA program consisted of center-based exercise sessions $3 \times$ weekly for 8 weeks, $2 \times$ weekly for weeks 9 to 24 and weekly behavioral counseling for 10 weeks. Optional sessions were offered during maintenance weeks (25-52). The comparison intervention consisted of weekly education meetings for 24 weeks, and then monthly for 6 months. Cost analyses were conducted from the "payer's" perspective, with a 1-year time horizon. Intervention costs were estimated by tracking personnel activities and materials used for each intervention and multiplying by national unit cost averages. The average cost/participant was $\$ 1134$ and $\$ 175$ for the PA and the comparison interventions, respectively. A preliminary cost/effectiveness analysis gauged the cost/disability avoided to be $\$ 28,206$. Costs for this PA program for older adults are comparable to those of other PA interventions. The results are preliminary and a longer study is required to fully assess the costs and health benefits of these interventions.

Groessl is with the Dept of Family and Preventive Medicine, University of California-San Diego, CA. Kaplan is with the Dept of Health Services, University of California-Los Angeles, CA. Blair is with the Dept of Exercise Science, University of South Carolina, Columbia, SC. Rejeski and Katula are with the Dept of Health and Exercise Science, Wake Forest University, Winston-Salem, NC. King is with the Dept of Health Research \& Policy and Medicine, Stanford University, Palo Alto, CA. Fielding is with the Nutrition, Exercise Physiology, and Sarcopenia Laboratory, Jean Mayer USDA Human Nutrition Research Center on Aging at Tufts University, Boston, MA. Glynn is with the Dept of Epidemiology, University of Pittsburgh, PA. Pahor is with the Dept of Aging and Geriatric Research, University of Florida, Gainesville, FL.
Keywords: aging, health behavior, physical activity, interventions

Impaired mobility, defined as being able to "walk safely and independently," ${ }^{1}$ is common among older adults and has been found to predict broader disability involving activities of daily living and independence.,2,3 A subgroup of the older adult population at risk for future disability ${ }^{4-7}$ is characterized by a sedentary lifestyle and impaired mobility. More specifically, high risk older adults walk more slowly and have reduced strength and balance but can still perform most daily living activities.

In an attempt to address the needs of this high risk population and prevent them from becoming more fully disabled, an intensive physical activity intervention has been developed and evaluated in the Lifestyle Interventions and Independence for Elders Pilot Study (LIFEP), a randomized controlled trial of physical activity compared with a "successful aging" educational intervention. After 12 months, participants randomly assigned to the physical activity (PA) intervention were less likely to reach the endpoint of major mobility disability in comparison with participants in the successful aging (SA) comparison group. ${ }^{8}$ Major mobility disability was defined as the inability to complete a $400-\mathrm{m}$ walk. ${ }^{9}$ In addition, participants in the PA group had significantly higher mean scores on the Short Physical Performance Battery (SPPB) and faster mean walking times in the 400-m walk.

Physical activity interventions can vary widely in their methodology, intensity, and the amount of resources required to conduct them. ${ }^{10-14}$ In this paper, we examine the resources required to achieve the health benefits associated with the physical activity intervention in the (LIFE-P) study.

\section{Methods}

Data for this study were collected in 2004 to 2006 and analyses were conducted in 2007 to 2008. Detailed descriptions of the design and methods ${ }^{9}$ and primary outcomes of the Lifestyle Interventions and Independence 
for Elders pilot (LIFE-P) study have been published. ${ }^{8}$ We provide a brief summary of the clinical trial and analytic methods below.

\section{Clinical Trial}

The LIFE-P study is a multisite, randomized controlled trial (RCT) in which older adults who were sedentary and at risk for disability were randomly assigned to either a physical activity (PA) intervention or a Successful Aging (SA) intervention. The interventions were 12 months in duration, with some data being collected out to 18 months. The goal of the LIFE-P study was to obtain key design benchmarks in preparation for a larger, full-scale study, particularly the rate of incident mobility disability based on a $400-\mathrm{m}$ walk test. ${ }^{15}$ The primary outcome of the pilot was the Short Physical Performance Battery (SPPB) score. ${ }^{5}$

\section{Interventions}

Physical Activity Intervention. The physical activity intervention included aerobic, strength, flexibility, and balance training and the intervention was structured into 3 phases: adoption (weeks 1 to 8); transition (weeks 9 to 24); and maintenance (week 25 to end of trial) (Table 1and Table 2). The initial contacts were primarily center-based with a shift to home-based activity in the transition and maintenance phases. The intervention was designed to be consistent with the public health message from the Surgeon General's report that moderate physical activity should be performed for 30 minutes on most, preferably all, days of the week (150-210 total minutes).
For the first 8 weeks (adoption), 3 supervised center-based physical activity group instruction sessions per week were conducted. These sessions were used to initiate the walking program and to introduce participants to the strength, stretching, and balance portions of the program in a safe and effective manner. These sessions involved approximately 40 to 60 minutes of physical activity instruction. Instructors had a minimum of a Bachelor's degree in exercise science or a related discipline with experience supervising physical activity programs. Exercise instructors were assisted by a nondegreed exercise facilitator. Throughout the adoption phase, physical activity instruction was supplemented with 30 minutes of group-based behavioral skills training (10 scheduled sessions total). In addition to these group sessions, individual monthly telephone contacts were used to discuss physical activity participation both within and outside of the supervised setting.

During weeks 9 to 24 of the program (transition), the number of center-based sessions was reduced to 2 times per week. These sessions were supplemented by home-based endurance/strengthening/flexibility exercises as a means of promoting physical activity in multiple settings. Individual monthly telephone contacts were also continued.

In the maintenance phase (weeks 25 to end of trial) participants were encouraged to perform home-based physical activity a minimum of 5 days per week. In addition, once-per-week center-based group physical activity sessions were offered to all PA participants (attendance was optional). Monthly, brief telephone contacts were continued to reinforce physical activity participation.

Walking was employed as the primary mode of physical activity, given its widespread acceptance in the older

Table 1 LIFE-P Intervention Schedule (Physical Activity Intervention)

\begin{tabular}{|c|c|c|c|c|}
\hline Phase & $\begin{array}{l}\text { Center-based } \\
\text { physical activity }\end{array}$ & $\begin{array}{l}\text { Behavioral group } \\
\text { counseling sessions }\end{array}$ & $\begin{array}{l}\text { Home-based* } \\
\text { physical activity }\end{array}$ & $\begin{array}{l}\text { Telephone } \\
\text { counseling }\end{array}$ \\
\hline $\begin{array}{l}\text { Adoption } \\
\text { (weeks1-8) }\end{array}$ & 3 times each week & $\begin{array}{l}8 \text { scheduled meetings, } \\
\text { immediately following a } \\
\text { scheduled center-based, } \\
\text { physical activity session }\end{array}$ & Up to 2 times per week & $\begin{array}{l}1 \text { time per } \\
\text { month }\end{array}$ \\
\hline $\begin{array}{l}\text { Transition } \\
\text { (weeks 9-24) }\end{array}$ & 2 times each week & 2 scheduled meetings & 3 times per week & $\begin{array}{l}1 \text { time per } \\
\text { month }\end{array}$ \\
\hline $\begin{array}{l}\text { Maintenance } \\
\text { (weeks 25-end of } \\
\text { trial) }\end{array}$ & Offered once per week & & $\begin{array}{l}5 \text { times or more per } \\
\text { week }\end{array}$ & $\begin{array}{l}1 \text { time per } \\
\text { month }\end{array}$ \\
\hline
\end{tabular}

Table 2 LIFE-P Intervention Schedule (Successful Aging Intervention)

\begin{tabular}{ll}
\hline Phase & Center-based health education classes \\
\hline Weeks 1-26 & weekly \\
Weeks 27-52 & monthly \\
\hline
\end{tabular}


adult population. Participants were introduced to the intervention exercises gradually over the first 2 to 3 weeks of the intervention with progression toward a general weekly walking goal of 150 minutes at a moderate intensity. Each session was preceded by a brief warm-up and followed by a brief cool-down period. Following each bout of walking, participants were instructed on brief lower extremity flexibility exercises, a 10-minute program of lower extremity strength training, and a structured balance-training program. Heart rate and blood pressure were also monitored weekly during the walking portion of the center-based sessions to ensure participant safety.

To encourage participation, phone call reminders were made to all participants by administrative personnel. Exercise equipment was purchased and provided to participants by the study. Examples include pedometers, ankle weights, exercise videotapes, water bottles. Refreshments were provided to participants at the initial orientation sessions. Water and small snacks were available at the center-based physical activity sessions since some participants were diabetic, and others may have come directly from work or other activities. Other participant incentives included a canvas tote bag to carry exercise equipment, sun-visors, coffee mugs, and an exercise t-shirt with the LIFE study name and logo. Materials consisted of instructional materials, copies/handouts, posters, and holiday greeting cards to encourage retention.

Successful Aging Intervention. The Successful Aging (SA) intervention served as an active control group for the physical activity intervention. SA participants attended weekly classes for the first $26 \mathrm{wk}$ and then monthly until the end of the trial. Health educators provided instructional lectures on health topics that are relevant to older adults, such as nutrition, medication use, foot care, and preventive medicine. All SA participants received basic information about physical activity participation, and each SA class concluded with a short, instructor-led, upper extremity stretching program. Regular monthly telephone contact was made to encourage participation and follow-up on missed sessions.

\section{Participants}

Participants were 424 sedentary older adults considered at risk for disability. Participant characteristics are shown in Table 3 and have been described previously. ${ }^{8,16,17}$ Inclusion criteria for the study were a) ages 70 to 89 years; b) at risk for mobility disability (SPPB score of $<10$ ); c) sedentary lifestyle (not actively participating in 20 minutes or more of formal exercise at least once a week within the past 3 months); d) ability to complete a $400 \mathrm{~m}$ walk test (usual pace) within 15 minutes without sitting or the use of an assistive device; e) successful completion of a behavioral run-in (consisting of completion of behavioral logs); and f) willingness to be randomized to either treatment group. Exclusion criteria included history of significant heart disease, currently taking steroids for lung disease, severe arthritis, cancer requiring treatment in the last 3 years, neurological disease, or current presence of psychotic disorders or alcohol problems. Comprehensive exclusion criteria ${ }^{17}$ and details of the design 9 are given elsewhere. Participants were recruited over the course of 9 months at 4 different regional sites (Dallas, TX; Pittsburgh, PA; Palo Alto, CA; Winston-Salem, NC) via fliers, mailings, community events, and advertisements (newspaper, radio, television). The recruitment goals were to randomize 400 participants (100 per site) including at least $30 \%$ men and $25 \%$ ethnic minorities.

\section{Measures}

Mobility. Mobility was measured using a timed 400-m walk. Each person was timed with a stopwatch during completion of a 400-m self-paced walk without sitting and without the use of an assistive device (including a cane) or the help of another person. ${ }^{18}$

Table 3 Participant Characteristics

\begin{tabular}{|c|c|c|}
\hline Variable & $\begin{array}{l}\text { Physical } \\
\text { activity }\end{array}$ & $\begin{array}{l}\text { Successful } \\
\text { aging }\end{array}$ \\
\hline Number & 213 & 211 \\
\hline \multicolumn{3}{|l|}{ Gender } \\
\hline Female & $146(68.5 \%)$ & $146(69.2 \%)$ \\
\hline Male & $67(31.5 \%)$ & $65(30.8 \%)$ \\
\hline \multicolumn{3}{|l|}{ Ethnicity } \\
\hline African-American/Black & $37(17.4 \%)$ & $40(19.0 \%)$ \\
\hline Caucasian/White & $163(76.5 \%)$ & $158(74.9 \%)$ \\
\hline Asian/Pacific Islander & $2(0.9 \%)$ & $2(0.9 \%)$ \\
\hline Other/mixed & $8(3.8 \%)$ & $8(3.8 \%)$ \\
\hline Refused/missing & $1(0.5 \%)$ & $1(0.5 \%)$ \\
\hline Non-Hispanic & $202(94.8 \%)$ & $200(94.8 \%)$ \\
\hline Hispanic & $10(4.7 \%)$ & $10(4.7 \%)$ \\
\hline Unknown & $1(0.5 \%)$ & $1(0.5 \%)$ \\
\hline \multicolumn{3}{|l|}{ Age } \\
\hline $70-74$ & $72(33.8 \%)$ & $75(35.5 \%)$ \\
\hline $75-79$ & $88(41.3 \%)$ & $74(35.1 \%)$ \\
\hline $80-84$ & $48(22.5 \%)$ & $56(26.5 \%)$ \\
\hline $85+$ & $5(2.3 \%)$ & $6(2.8 \%)$ \\
\hline \multicolumn{3}{|l|}{ Education } \\
\hline Elementary school & $5(2.3 \%)$ & $6(2.8 \%)$ \\
\hline High school or equivalent & $58(27.2 \%)$ & $58(27.5 \%)$ \\
\hline College & $106(49.8 \%)$ & $88(41.7 \%)$ \\
\hline Post graduate & $36(16.9 \%)$ & $54(25.6 \%)$ \\
\hline Other & $7(3.3 \%)$ & $5(2.4 \%)$ \\
\hline Missing & $1(0.5 \%)$ & $0(0.0 \%)$ \\
\hline
\end{tabular}


Physical Functioning. Physical functioning was measured using the Short Physical Performance Battery (SPPB). ${ }^{5}$ The SPPB assesses 3 areas of performance: balance, chair stands, and a 4-m self-paced walking speed. Function in each of these 3 areas is assigned a categorical score ranging from 0 to 4 , with 4 being the highest performance level and 0 indicating an inability to complete the test. A summary score ranging from 0 (worst performers) to 12 (best performers) is calculated by adding the 3 subscale area scores together.

Major Mobility Disability. The 400-m walk and SPPB scores are used to predict and measure progression toward the more distal outcome of major mobility disability. In the LIFE-P study, major mobility disability was defined as the inability to complete the $400 \mathrm{~m}$-walk within $15 \mathrm{~min}$. without the help of another person. If the $400 \mathrm{~m}$-walk could not be initiated or completed by a participant, the outcome was adjudicated by a masked panel of experts. More details on the adjudication process are provided in recent publications. $^{8}$

\section{Cost Analysis}

An analysis of costs was conducted from the "payer's" perspective. This organizational perspective might best represent the costs that a healthcare system may incur when offering interventions of this type. The "payer's" perspective will allow healthcare organizations to gauge approximately what it would cost for them to conduct a similar program in the future, assuming adjustments are made for inflation. Thus, home-based exercise costs, travel time, and other societal costs are not included in the analysis. The time horizon for the analysis was 1 year based on the available data from the study. Intervention costs were based on the actual personnel time and materials used in the LIFE-P study and are detailed in the next section. Overhead costs were estimated at $69 \%$ of the personnel costs required to deliver the intervention. The overhead cost estimate accounts for facilities costs, indirect support personnel, and other typical indirect costs associated with running an outpatient healthcare program. ${ }^{19}$ This figure of $69 \%$ is based on data showing that only half of all healthcare reimbursement costs are related to direct provision of care ${ }^{20}$ and that roughly $69 \%$ of noncare costs are indirect costs. ${ }^{21}$ This method has been used in the cost analyses of other similar trials. ${ }^{11}$ All research related activities were excluded from the cost analysis.

\section{Intervention Costs}

Intervention costs for each intervention were calculated by counting the total number of intervention sessions delivered for each group. All intervention sessions and participant attendance were tracked in the records of each of the 4 research sites. Next, in collaboration with the exercise intervention investigators, we estimated the mean time required for each intervention staff member to deliver 1 session. Finally, each unit of staff time was multiplied by the mean national hourly wage for each position (obtained from the US Bureau of Labor Statistics 2007). ${ }^{22}$ Because exact matches between national occupation categories and intervention positions were not always available, the closest available position was used. For example, Job \#29-9099 Healthcare Practitioner and Technical Workers $(\$ 22.94 /$ hour) was used for the Exercise Interventionist since Fitness Trainers and Aerobic Instructors (Job \# 39-9031— \$15.86/hour) often do not have a Bachelor's degree. Mean hourly wage for the Exercise Facilitator/Assistant were obtained from Job \#31-0000 Healthcare Support Occupations (\$12.31/hour). Mean hourly wage for the Health Educator was obtained from Job \#21-2091 Health Educators (\$22.76.hour). All hourly wage rates were multiplied by 1.332 to adjust for the national average for fringe benefits. For the purposes of calculating hourly wages, paid leave was added to fringe benefits. ${ }^{23}$

Actual expenditures on exercise equipment were tracked by study personnel. Due to variations between sites, the average cost per participant of exercise equipment across all sites was calculated. Phone charges were estimated because data on actual phone charges included both research and intervention costs and could not be clearly separated. The number of telephone counseling sessions and scheduled physical activity sessions were multiplied by the estimated time spent for each call made for phone counseling and intervention reminders. These were multiplied by $\$ 0.06$ per minute or $\$ 3.60$ per hour. All materials used to deliver the 2 interventions were tracked and actual costs were recorded by study personnel. Costs for refreshments and participant incentives were tracked at each site before being totaled and divided by the number of total participants for that intervention. Recruitment costs were not included in the analysis because it was not possible to separate research recruitment from intervention recruitment in this study. Overall recruitment costs are described elsewhere. ${ }^{17}$

Cost-Effectiveness. To calculate an incremental costeffectiveness ratio for the intervention, we subtract the costs of the control group (Successful Aging) from the intervention group (Physical Activity) to get the incremental cost per participant. Next, we subtract the improvement in disability between the intervention and control group. Finally, we divide the incremental cost per participant by the incremental effectiveness to get the ratio. The incidence of progression of participants to major mobility disability provided the most clinically meaningful measure of effectiveness. To be enrolled in the study, participants had to be able to complete the $400 \mathrm{~m}$ walk within 15 minutes at the baseline assessment. Previously reported results ${ }^{8}$ indicate that $33 / 211$ 
or $15.6 \%$ of the participants in the Successful Aging intervention progressed to major mobility disability while 26/213 or $12.2 \%$ of participants in the Physical Activity intervention met this criteria after 12 months.

\section{Results}

The 424 participants were 77 years of age on average, $69 \%$ women, $74 \%$ white, $80 \%$ married or widowed, $67 \%$ had attended college, and their median income was in the $\$ 25,000$ to $\$ 50,000$ range. ${ }^{16,22}$

\section{Intervention Costs}

The direct costs of the LIFE-P Physical Activity (PA) and Successful Aging (SA) interventions are presented in Table 4. Costs were estimated based on the actual numbers of each element of the intervention that were delivered. Each project activity was carefully evaluated to determine whether it served research purposes or served intervention purposes, and would be delivered if the intervention were deemed effective and adopted clinically in the future.

A total of 2080 center-based group physical activity sessions were held across all 4 sites during the first
12 months of the intervention. Dividing this number by the total number of participants in the physical activity intervention $(\mathrm{n}=213)$, we found that 9.76 sessions were held per participant. Personnel required to provide each session of the PA intervention consisted of an Exercise Interventionist assisted by an Exercise Facilitator. There were also 285 group Behavioral Counseling sessions provided by an behavioral counseling specialist, resulting in 1.34 sessions per participant. Total costs per participant for the Physical Activity intervention were estimated to be $\$ 1,134$.

For the Successful Aging intervention, 441 interventions sessions were held across all 4 sites, resulting in 2.09 sessions per participant. Each successful aging intervention was provided by trained Health Educator. Like the PA intervention, phone call reminders were made by administrative personnel to all participants to encourage participation, basic refreshments were provided at group sessions, and materials were required primarily for instruction purposes, but also for participant retention. Total costs per participant for the Successful Aging intervention were estimated to be $\$ 175$.

Therefore, the incremental difference in this outcome between the 2 interventions is $3.4 \%$. Subtracting $\$ 175$ from $\$ 1134$, we find the incremental cost per

Table 4 Direct Costs of the Physical Activity and Successful Aging Interventions

\begin{tabular}{|c|c|c|c|c|c|}
\hline \multicolumn{6}{|c|}{ Physical activity } \\
\hline Item & Provider & Units & $\begin{array}{c}\text { Time } \\
\text { (h) }\end{array}$ & Cost/hour & $\begin{array}{c}\text { Total \$ } \\
\text { cost/ } \\
\text { participant }\end{array}$ \\
\hline \multirow[t]{2}{*}{ Physical activity sessions } & Exercise interventionist & 9.76 & 0.87 & $\$ 30.56$ & 259 \\
\hline & Facilitator/assistant & 9.76 & 0.87 & $\$ 16.40$ & 139 \\
\hline Behavioral counseling & Exercise interventionist & 1.34 & 0.5 & $\$ 30.56$ & 20 \\
\hline Telephone counseling & Exercise interventionist & 12 & 0.17 & $\$ 30.56$ & 62 \\
\hline Phone call reminders & Facilitator/assistant & 84 & 0.033 & $\$ 16.40$ & 45 \\
\hline Exercise equipment & & & & & 129 \\
\hline Phone charges-counsel & & 12 & 0.20 & 3.6 & 9 \\
\hline Phone charges-reminders & & 84 & 0.033 & 3.6 & 10 \\
\hline Materials & & & & & 78 \\
\hline Refreshments/incentives & & & & & 21 \\
\hline Overhead ( $69 \%$ of personnel costs) & & & & & 362 \\
\hline Total cost/ participant & & & & & 1134 \\
\hline \multicolumn{6}{|c|}{ Successful aging } \\
\hline Intervention sessions & Health educator & 2.09 & 0.87 & $\$ 30.32$ & 55 \\
\hline Phone call reminders & Facilitator/assistant & 32 & 0.033 & $\$ 16.40$ & 17 \\
\hline Phone charges & & 32 & 0.033 & 3.6 & 4 \\
\hline Materials & & & & & 34 \\
\hline Refreshments/incentives & & & & & 15 \\
\hline Overhead ( $69 \%$ of personnel costs) & & & & & 50 \\
\hline Total cost/participant & & & & & 175 \\
\hline
\end{tabular}


Table 5 Incremental Cost-Effectiveness

\begin{tabular}{cccccc}
\hline & $\begin{array}{c}\text { Total costs } \$ \text { / } \\
\text { participant }\end{array}$ & $\begin{array}{c}\text { Proportion } \\
\text { becoming } \\
\text { disabled }\end{array}$ & $\begin{array}{c}\text { Incremental } \\
\text { cost }\end{array}$ & $\begin{array}{c}\text { Incremental } \\
\text { reduced disability }\end{array}$ & $\begin{array}{c}\text { Incremental } \\
\text { C/E }\end{array}$ \\
\hline Successful aging & 175 & $33 / 211$ & - & - & \\
Physical activity & 1134 & $(15.6 \%)$ & & $3.4 \%$ & $\$ 28,206 /$ disabil- \\
& & $26 / 213$ & & & ity avoided \\
\hline
\end{tabular}

participant to $\$ 959$ per participant. As shown in Table 5 , dividing $\$ 959$ by 0.034 (3.4\%) provides an incremental cost-effectiveness ratio of $\$ 28,206$ per major mobility disability avoided.

\section{Discussion}

Previously published results describing the LIFE-P study physical activity intervention suggest that older adults who adhere to a physical activity intervention can improve their mobility. ${ }^{8,9,16} \mathrm{An}$ important next step is to evaluate the resources required to deliver this intervention and produce the health benefit. Thus, our objective was to describe the resources required for an organization to provide the intervention from the LIFE-P and to conduct a preliminary cost-effectiveness analysis.

It was estimated that the physical activity intervention would cost $\$ 1134$ per participant to deliver over the course of 1 year; an incremental cost of \$959/participant over the comparison group. This amount is less than the first year costs for a comparable physical activity intervention conducted as part of the Diabetes Prevention Program. ${ }^{11}$ Part of the cost difference may be explained by the LIFE-P physical activity intervention having more group exercise sessions than the DPP intervention, and less time spent on individualized instruction and behavioral counseling. An interesting study by Sevick et $\mathrm{al}^{13}$ compared 2 different types of exercise interventions and found that a behaviorally-based lifestyle intervention cost much less than an exercise intervention consisting of supervised in-center exercise and paid health club memberships. These interventions cost $\$ 279$ (behaviorally-based) and $\$ 1140$ (supervised) respectively in just the first 6 months of the program, but are hard to compare with the LIFE-P intervention. The LIFE-P intervention was more intensive than the behaviorally-based intervention in Project ACTIVE, incorporating both behavioral counseling and center-based exercise, but encouraged a transition to home-based exercise instead of using more expensive health club memberships. One important question is whether the costs might change depending on the context in which they are offered in, or whether costs could be intentionally reduced without diminishing the effectiveness results. Sensitivity analyses can easily be conducted by varying the average hourly wage obtained from the US Dept of Labor ${ }^{22}$ for personnel, or by varying the amount of indirect costs associated with personnel costs. Different results are expected depending on geographical location and other factors. It would be useful, for instance, to evaluate the specific utility of the telephone contacts over and above the class-based sessions and instruction for this target population. Another source of cost variability may be the average attendance per intervention session. The cost analysis above used the actual number of sessions offered and early sessions were well attended. Later in the year, as participants transitioned to home-based exercise, there were fewer participants per session, resulting in less efficiency. Improving this overall ratio of participant attendance per session could significantly reduce the cost of providing the physical activity intervention, but further research is needed to also demonstrate that effectiveness outcomes are maintained.

The preliminary cost-effectiveness ratio of roughly $\$ 28,000 /$ major mobility disability avoided is difficult to put in context. We could not find other studies that report cost data per unit of major mobility disability avoided. This has been a common problem in costeffectiveness literature and can be avoided by using common units of effectiveness for the analysis, such as quality-adjusted life years (QALYs). ${ }^{24}$ However, our analysis is preliminary because of the short follow-up period, and the use of QALYs with such a short time horizon would make interpretation just as challenging. As seen in the DPP study, ${ }^{11,25}$ the benefits of intensive exercise programs often take 2 to 3 years to emerge while costs tend to drop at the same time. Thus, the short follow-up period is the primary limitation of this study. A more detailed cost-effectiveness study, complete with sensitivity analyses, and future decision modeling will be conducted when longer term data become available.

Another option for interpreting our findings would be to take a cost-benefit perspective, in which both the numerator and denominator are stated in terms of dollars. ${ }^{24} \mathrm{~A}$ recent report by Yelin et al estimates the economic impact of disability in the United States. ${ }^{26}$ Although a sizable portion of the economic cost of disability is attributed to lower wages and lost productivity, and thus, does not fully apply to most older adults, higher medical costs are still applicable. In fact, the increased medical costs resulting from disability or its precursors would likely be considerably higher than 
those estimated for all adults 18 years of age and older. Regardless, the results may not be comparable because the definition of disability in the Yelin study differs from that in the LIFE-P study.

Although the healthcare utilization and estimated cost data are of more limited value when analyzing costs from an organizational perspective, the data indicate that neither intervention produced a differential effect on healthcare utilization. This finding coincides with LIFE-P data on adverse events reported in an earlier publication. Those data showed that adverse events were roughly equivalent in the 2 study groups across the relatively short (ie, 1 year) study intervention period.

Recruitment costs were not directly incorporated into the cost estimates because of the challenges in separating research versus intervention recruitment costs. Recruitment within a research study is typically much more intensive and costly by necessity, since grant funding and recruitment timelines are very time limited, and additional effort and costs are required to conduct baseline evaluations that are more extensive than a typical clinical examination. Recruitment costs may also vary widely depending on the organization, with clinical providers referring patients directly to physical activity programs in some settings, while a community senior center may need to recruit interested parties more quickly to initiate the program at all. Thus, organizations should add some cost per participant to the estimates presented above. This should not affect the results or conclusions presented above because similar recruitment costs might be expected for both the physical activity and the successful again interventions. However, our experience with the LIFE-P study indicated that the physical activity intervention was more attractive to potential participants. If measurable, this difference in attractiveness could translate into recruitment being easier and less costly for the more attractive intervention, and reduce the incremental cost of the physical activity intervention.

In summary, the intensive physical activity intervention studied in LIFE-P was comparable in cost to other similar interventions and improved mobility in older adults. Cost analyses provide researchers and health policy decision-makers with valuable information needed to evaluate health interventions. The current study is limited primarily by a short follow-up period and a more detailed cost-effectiveness analysis will be conducted when longer term data become available from future studies.

\section{Acknowledgments}

The Lifestyle Interventions and Independence for Elders (LIFE) Pilot Study is funded by National Institutes on Health/ National Institute on Aging Cooperative Agreement \#UO1 AG22376 and sponsored in part by the Intramural Research Program, National Institute on Aging, NIH. This material is based upon work supported by the U.S. Department of Agriculture, Agricultural Research Service, under agreement
No. 68-1950-7-707. Any opinions, findings, conclusion, or recommendations expressed in this publication are those of the author(s) and do not necessarily reflect the view of the U.S. Dept of Agriculture.

\section{References}

1. Patla AE, Shumway-Cook A. Dimensions of mobility: defining the complexity and difficulty associated with community mobility. J Aging Phys Act. 1999;7(1):7-19.

2. Fried LP, Bandeen-Roche K, Chaves PH, Johnson BA. Preclinical mobility disability predicts incident mobility disability in older women. J Gerontol A Biol Sci Med Sci. 2000;55(1):M43-M52.

3. Guralnik JM, LaCroix AZ, Abbott RD, et al. Maintaining mobility in late life. I. Demographic characteristics and chronic conditions. Am J Epidemiol. 1993;137(8):845857.

4. Ferrucci L, Penninx BW, Leveille SG, et al. Characteristics of nondisabled older persons who perform poorly in objective tests of lower extremity function. J Am Geriatr Soc. 2000;48(9):1102-1110.

5. Guralnik JM, Ferrucci L, Simonsick EM, Salive ME, Wallace RB. Lower-extremity function in persons over the age of 70 years as a predictor of subsequent disability. N Engl J Med. 1995;332(9):556-561.

6. Guralnik JM, Leveille S, Volpato S, Marx MS, CohenMansfield J. Targeting high-risk older adults into exercise programs for disability prevention. J Aging Phys Act. 2003;11:219-228.

7. Guralnik JM, Simonsick EM, Ferrucci L, et al. A short physical performance battery assessing lower extremity function: association with self-reported disability and prediction of mortality and nursing home admission. $J$ Gerontol. 1994;49(2):M85-M94.

8. The LIFE Study Investigators. Effects of a physical activity intervention on measures of physical performance: results of the Lifestyle Interventions and Independence for Elders pilot (LIFE-P) study. Journal of Gerontology: Medical Sciences. 2006;61A(11):1157-1165.

9. Rejeski WJ, Fielding RA, Blair SN, et al. The lifestyle interventions and independence for elders (LIFE) pilot study: design and methods. Contemp Clin Trials. 2005;26(2):141-154.

10. Bulthuis Y, Mohammad S, Braakman-Jansen LM, Drossaers-Bakker KW, van de Laar MA. Cost-effectiveness of intensive exercise therapy directly following hospital discharge in patients with arthritis: Results of a randomized controlled clinical trial. Arthritis Rheum. 2008;59(2):247-254.

11. Herman WH, Brandle M, Zhang P, et al. Costs associated with the primary prevention of type 2 diabetes mellitus in the diabetes prevention program. Diabetes Care. 2003;26(1):36-47.

12. Patrick DL, Ramsey SD, Spencer AC, Kinne S, Belza B, Topolski TD. Economic evaluation of aquatic exercise for persons with osteoarthritis. Med Care. 2001;39(5):413424. 
13. Sevick MA, Dunn AL, Morrow MS, Marcus BH, Chen GJ, Blair SN. Cost-effectiveness of lifestyle and structured exercise interventions in sedentary adults: results of project ACTIVE. Am J Prev Med. 2000;19(1):1-8.

14. van den Hout WB, de Jong Z, Munneke M, Hazes JM, Breedveld FC, Vliet Vlieland TP. Cost-utility and costeffectiveness analyses of a long-term, high-intensity exercise program compared with conventional physical therapy in patients with rheumatoid arthritis. Arthritis Rheum. 2005;53(1):39-47.

15. Newman AB, Haggerty CL, Kritchevsky SB, Nevitt MC, Simonsick EM. Walking performance and cardiovascular response: associations with age and morbidity-the Health, Aging and Body Composition Study. J Gerontol A Biol Sci Med Sci. 2003;58(8):715-720.

16. Fielding RA, Katula J, Miller ME, et al. Activity adherence and physical function in older adults with functional limitations. Med Sci Sports Exerc. 2007;39(11):19972004.

17. Katula JA, Kritchevsky SB, Guralnik JM, et al. Lifestyle Interventions and Independence for Elders pilot study: recruitment and baseline characteristics. J Am Geriatr Soc. 2007;55(5):674-683.

18. Simonsick EM, Montgomery PS, Newman AB, Bauer DC, Harris T. Measuring fitness in healthy older adults: the Health ABC Long Distance Corridor Walk. J Am Geriatr Soc. 2001;49(11):1544-1548.

19. Latimer EA, Becker ER. Incorporating practice costs into the Resource-Based Relative Value Scale. Med Care. 1992;30(11, Suppl):NS50-NS60.
20. American Medical Association. Socioeconomic Characteristics of Medical Practice. Chicago: American Medical Association; 1991.

21. Physician Payment Review Commission. Practice Expenses Under the Medicare Fee Schedule: A ResourceBased Approach. Washington, DC: Physician Payment Review Commission; 1992.

22. US Department of Labor. Bureau of Labor Statistics. National Occupational Employment and Wage Estimates. http://www.bls.gov/oes/current/oes_nat.htm. Accessed October 2008.

23. Grosse SD. Productivity loss tables (Appendix I). In: Haddix AC, Teutsch SM, Corso PS, eds. Prevention Effectiveness: A Guide to Decision Analysis and Economic Evaluation. 2nd ed. London: Oxford University Press; 2003:245-257.

24. Gold MR, Siegel JE, Russell LB, Weinstein MC. Costeffectiveness in Health and Medicine. New York, NY: Oxford University Press; 1996.

25. Herman WH, Hoerger TJ, Brandle M, et al. The costeffectiveness of lifestyle modification or metformin in preventing type 2 diabetes in adults with impaired glucose tolerance. Ann Intern Med. 2005;142(5):323-332.

26. Yelin EH, Cisternas M, Trupin L. The economic impact of disability in the united states, 1997: total and incremental estimates. J Disabil Policy Stud. 2006;17:137. 